\title{
Monitoring Floods and Fires during the Summer of 2011- The Value of the Landsat Satellite 40-Year Archive
}

The summer of 2011 proved to be a season of extreme events. Heavy snowfall in the western mountains and excessive spring rains caused flooding along the Missouri and Mississippi Rivers; whereas extended dry conditions enabled fires to rage out of control from Alaska and Canada, south to Texas, Arizona, New Mexico, Georgia, and Mexico.

The Landsat archive holds nearly 40 years of continuous global earth observation data. Landsat data are used by emergency responders to monitor change and damage caused by natural and man-made disasters. Decision makers rely on Landsat as they create plans for future environmental concerns.

A sampling of incidents during the summer of 2011:
$\diamond$ Missouri River Flooding
$\diamond$ Mississippi River Flooding
$\diamond$ Horseshoe Fire, Arizona
$\diamond$ Monument Fire, Arizona
$\diamond$ Wallow Fire, Arizona
$\diamond$ Richardson Backcounty Fire, Alberta
$\diamond$ Los Conchas Fire, New Mexico
$\diamond$ Honey Prairie Fires, Georgia
$\diamond$ Coal Canyon Fire, South Dakota
$\diamond$ Lateral West Fire, Virginia
$\diamond$ Lightning Fires, Idaho

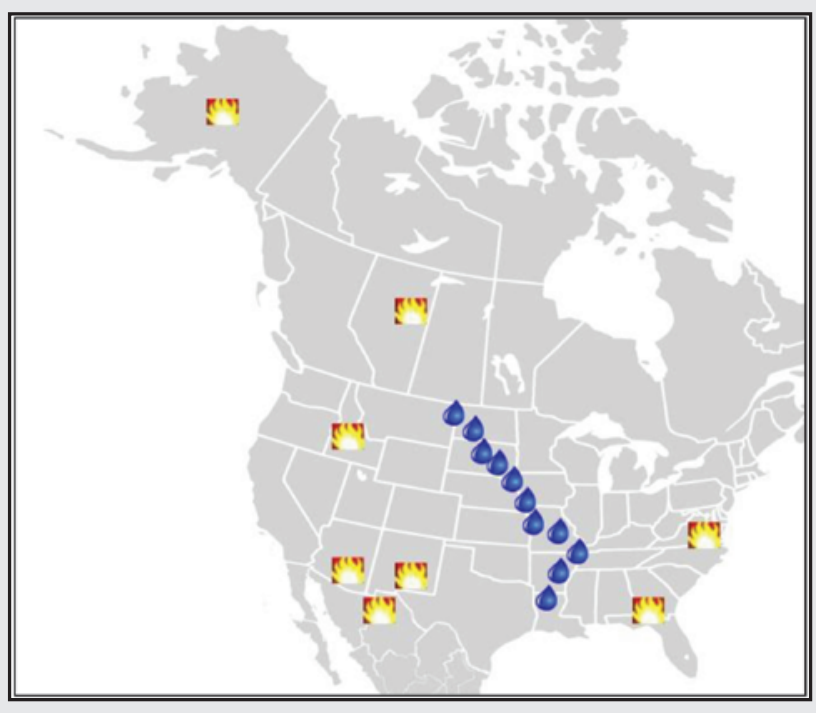

Summer 2011 fire and flooding activity (not all-inclusive).

\section{Missouri River Flooding, Midwestern United States}

Greater than normal snowfall in mountain ranges, coupled with heavy spring rainfall, proved challenging for the entire Missouri River Basin in 2011. Flooding was prevalent from Montana, winding through the Dakotas, then south to Iowa, Nebraska, and Missouri throughout the summer. Major highways, homes, businesses, and millions of acres of farmland were inundated.

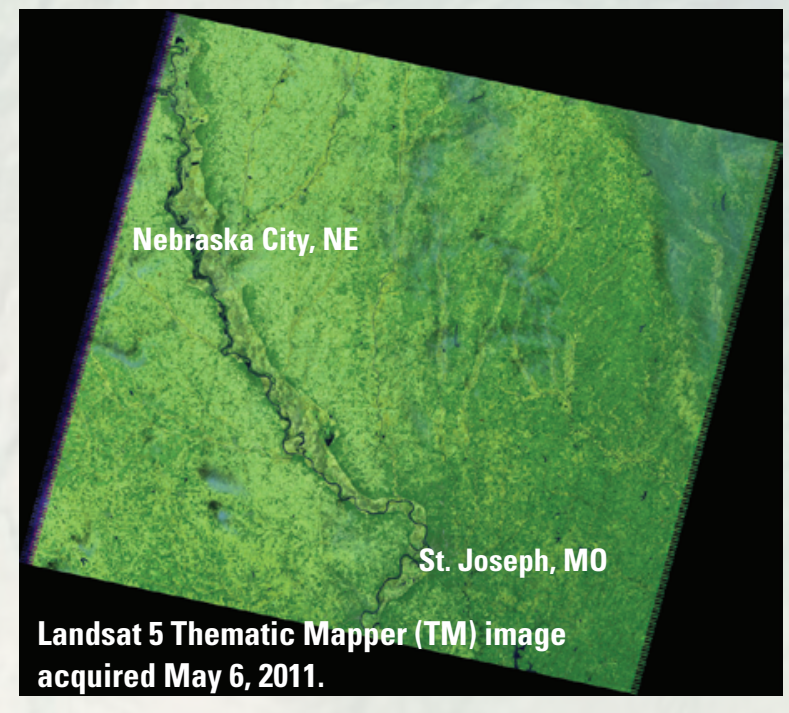

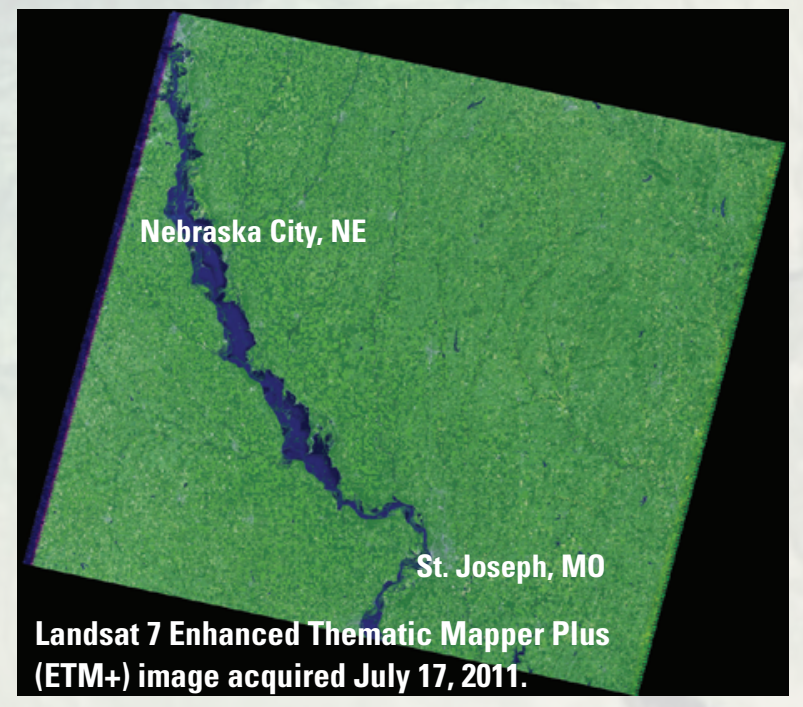




\section{Los Conchas Fire, New Mexico}

New Mexico's largest wildfire in recorded history began June 26, 2011, and threatened the town of Los Alamos and the Los Alamos National Laboratory. The fire was considered fully contained on August 3, 2011, only after damaging the Santa Fe National Forest.

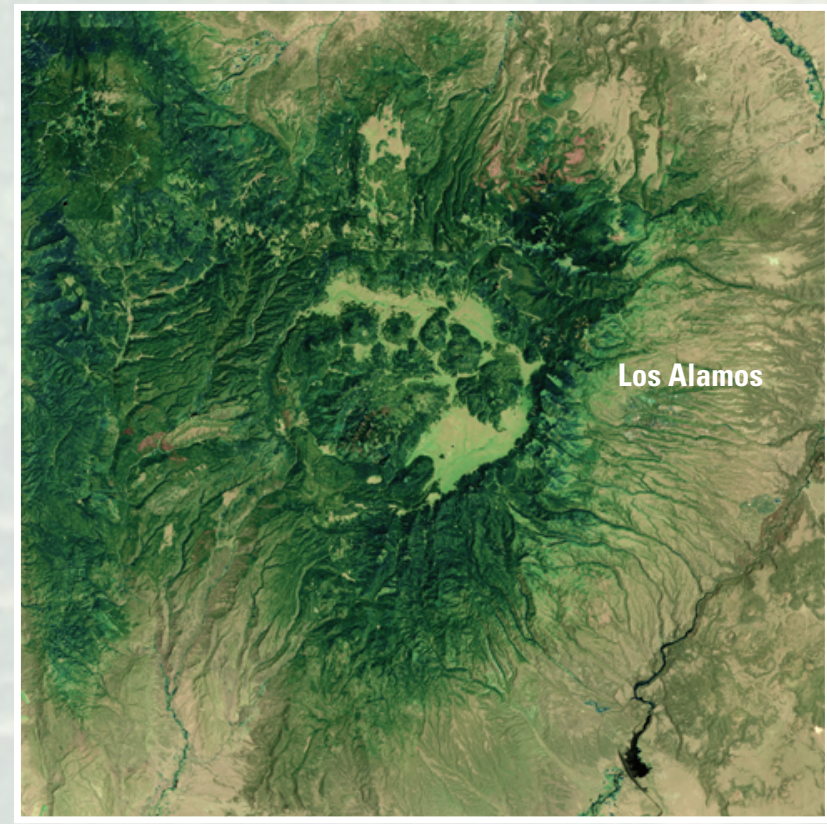

Landsat 5 Thematic Mapper (TM) image acquired June 24, 2011.

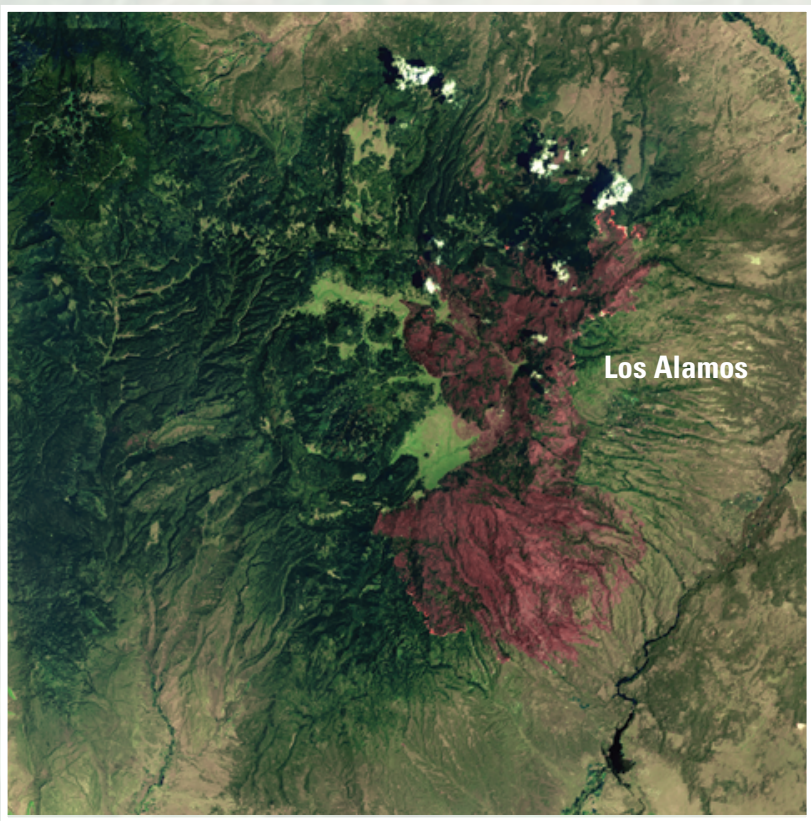

Landsat 7 Enhanced Thematic Mapper Plus (ETM+) image acquired July 2, 2011.

\section{Morganza Spillway, Louisiana}

Heavy rain in the Mississippi River Valley prompted the opening of the Morganza Spillway in central Louisiana on May 14, 2011. Opening the spillway relieved pressure on levees protecting Baton Rouge and New Orleans downstream but flooded the local area.

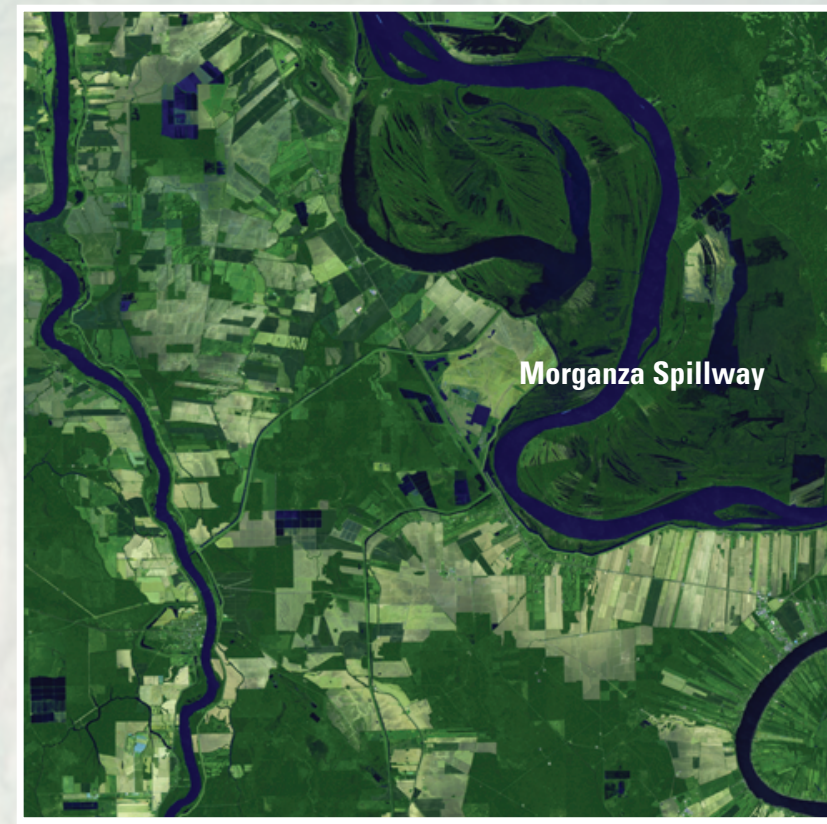

Landsat 7 Enhanced Thematic Mapper Plus (ETM+) image acquired April 16, 2011.

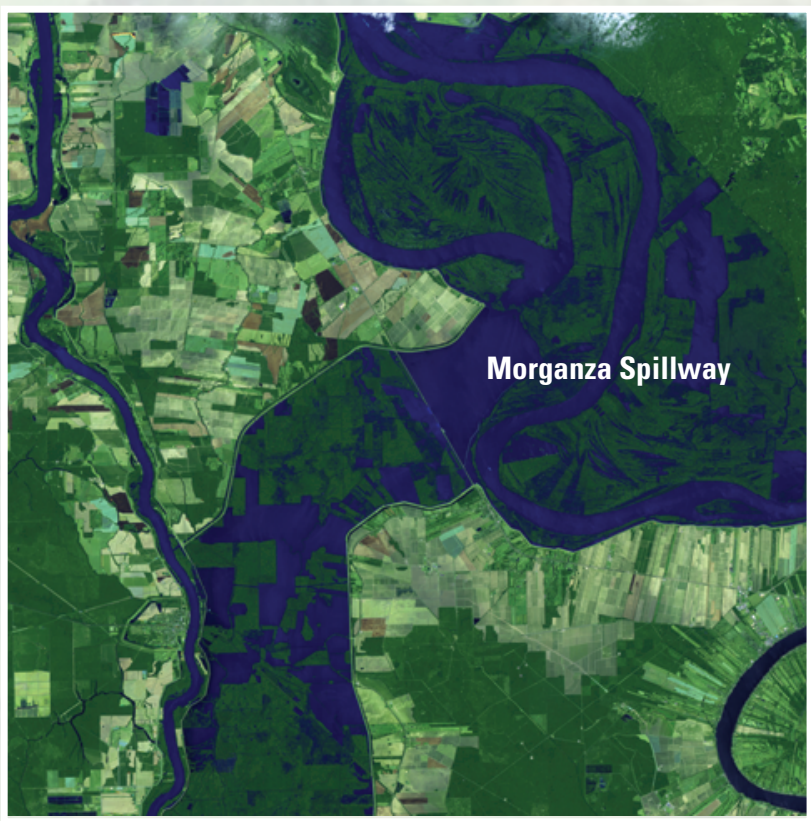

Landsat 7 Enhanced Thematic Mapper Plus (ETM+) image acquired May 18, 2011.

For more information on Landsat data products and to view additional images, visit http://landsat.usgs.gov. 